\title{
Family Literacy Practices Surrounding Homework
}

\author{
Kathy R. Fox \\ University of North Carolina Wilmington \\ North Carolina, USA
}

\begin{abstract}
Authentic literacy practices regarding homework in three demographically different family groups were the focus of this study. Language, economic level, and educational background were factors considered in the analysis from a series of parent interviews that occurred in homes, offices, and afterschool settings. Implications of the study encourage teachers to be conscious of the importance of homework as a tool for providing meaningful activity, communicating information to the home about the classroom curriculum and mainstream practices. Teachers are encouraged to see the bi-directional potential of homework as an opportunity for teachers to learn about family practices through the returned homework.
\end{abstract}

Samuel unpacks his school backpack, sitting on the sofa. Mrs. Ortega looks at each paper, making 2 stacks, one of the new homework and the second of the previous night's homework, checked by the teacher. When finished she passes the sheets to the two younger daughters, seated nearby on the floor by a low table. They proceed to use crayon to trace the numbers on the page. The older of the two traces Samuel's name and then adds her own, Mara, on the line next to his. Meanwhile, Samuel describes his new homework assignment to his mother in Spanish while reading the English text. The two younger sisters quietly work, listening to the conversation. Mrs. Ortega: "When he gets his papers they use them to practice their numbers and letters. She is going to be ready for kindergarten."

This excerpt from observation notes shows the collective approach to homework used by one of the diverse families included in this study, which examines homework as a differentiated practice in a variety of family settings. That is, how is homework addressed in the homes of children whose backgrounds differ from one another in terms of economics, parents' education levels, language status, and literacy level?

The practice of homework was examined through the eyes of the parents whose children received remarkably similar homework across schools, school districts, and even states. The 
ways in which homework was perceived, discussed, accomplished, and ultimately valued differed greatly among the families studied. In the opening instance, for example, homework is being used as a tool for practicing school-based English while at the same time as a prompt for maintaining academic discourse in the home language of Spanish. Participants in this phase of the study were members of an English as a Second Language (ESL) class designed for children with parents of minority language in an all-English classroom. Homework, in some cases, had consequences for the family beyond its original intent, where the parent extended its uses for the benefit of the rest of family; as when Mrs. Ortega describes how her first grader's homework and classwork pages were used as prompts for the two younger children not yet in school.

In a second setting, children's homework practices were examined in the homes of parents who were faculty members teaching in a university teacher education program. Parents were interviewed in their offices and asked to describe the homework and homework practices of their children and family. In a third setting, homework practices in the homes of families living in subsidized housing were examined. Parents were interviewed in their homes or at an afterschool site.

What we learned from the examination of these diverse family settings is that homework has different benefits, purposes, and results for families. This article presents a three-part study that examines diverse perspectives of homework from families influenced by economics, language background, and education levels. It describes the less-visible effects of homework from an additive, Funds of Knowledge perspective of family literacy (Moll, Amanti, Neff, \& Gonzalez, 2001), which is defined here as "the historically accumulated and culturally developed bodies of knowledge and skills essential for household or individual functioning and well-being" (p. 133). Rather than looking at family literacy practices from a negative, or deficit, perspective, such as the traditional view expressing the need for training for parents to work with their children (Amstutz, 2000; Colombo, 2005), the practices and beliefs parents and family members already have in place regarding homework are examined. The goal of understanding these different practices in order to design appropriate homework and other forms of family-school communications reflects what Edwards calls "parentally appropriate programs," stressing the point that "because parents are different, tasks and activities must be compatible with their capabilities" (Edwards, 2009, p. 83), interests, and preferred practices.

\section{Homework as an Element of Family Literacy}

Traditionally, in both the colloquial sense and in the literature on the subject, homework has been characterized as a negative and even potentially traumatic event, i.e., as a hassle (Beaulieu \& Granzin, 2004), as harmful to parent and child relationships (Bennett \& Kalish, 2007), with little to no positive effects (Kohn, 2007), or as causing emotional distress (DellAntonia, 2014), shown via sales of the popular Homework without Tears, which sold over 750,000 copies (Canter, Hausner, \& MacMahon, 1988). In a review of over 120 studies examining homework, Cooper describes a synthesis of findings around the negative effects of homework, citing "satiation, denial of leisure time, parental interference and cheating" (2001a). Adding to this negative characterization of homework is the recommendation of a somewhat isolated, non-participatory setting away from TV and phones with a parent as a monitor but not participant (Kidshealth, 2015). For optimum conditions, the setting traditionally recommended is "a quiet place, away from distractions, with ample room to work" (Spalding, 2004, 1).

Suggestions such as special lighting and a student sized desk are also mentioned. Although more 
recent studies acknowledge the role of parents in supporting their child's homework (Fox, 2003; Fox, 2010; California Department of Education, 2004), the majority of resources continue to describe the parents' role as checking the homework after completion (Beaulieu \& Granzin, 2004; Canter et al., 1988; Spalding, 2004; Unger, 1991). National Parent Teacher Organization guidelines recommend best practice for homework as: "Let your child know you will be available for proofreading, finding simple math mistakes, or writing a note to the teacher if he or she doesn't understand an assignment" (Vatterott, 2012).

In truth, what we know is that families live in diverse settings and situations, with their own sets of traditional practices and values that influence their concepts of parent involvement (Fox, 2010; Boethel, 2003; Chrispeels \& Gonzalez, 2006; Ho, Fox \& Gonzalez, 2007; Hong \& Ho, 2005). Anderson describes a more culturally relevant perspective on factors that influence parental involvement as generally not indicative of interest, but rather of opportunities that enhance or barriers that prevent schools from effectively engaging parents (2014). Culturally relevant pedagogy is defined as "using the cultural characteristics, experiences and perspectives of ethnically diverse students as conduits for teaching them more effectively" (Gay, 2002. p. 106). In the case of best practices for homework, culturally relevant pedagogy calls for teachers to see homework as a bi-directional opportunity to learn more about the family through more open-ended assignments, just as the family learns about the classroom through the homework (Reinemann, n.d.; Colombo, 2005; Cooper, 2001b). This study examines the less visible effects of homework from an additive perspective of family literacy, which is defined here as the link between children's literacy with that of their parents and siblings. Often family literacy programs seek to provide training and other services to raise literacy levels of underachieving parents in order to have a positive effect on that of the children (Amstutz, 2000). This study seeks to uncover what family members have in place to support homework completion as a form of family literacy from a Funds of Knowledge perspective (Moll et al., 2001) and to examine the benefits of homework as the families describe them.

\section{Methods}

The study was conducted in a sequential manner over ten years and in two settings: a small coastal city in Central California (Phase 1) and a second small coastal city in North Carolina (Phase 2 and Phase 3). Both settings boast diverse populations in terms of language, culture, religion, ethnicity, and economics. Likewise, both cities have a vibrant university presence.

\section{Phase 1: California. Homework in the homes of Spanish speaking families.}

Phase 1 of the study was conducted initially as a part of a larger four-year study examining afterschool English as a Second Language (ESL) classes for non-English speaking parents and their children that took place in four different elementary schools. The bi-weekly family literacy classes set at neighborhood elementary schools were designed to help parents and community members learn English as part of the public school policy shift from native language maintenance programs to an all-English mandated curriculum (California Tomorrow, 1998). The seven participating families were a convenience sample from one of the four participating schools. They volunteered their participation in this phase of the study as an ongoing part of their ESL class. 
The school population of 438 was identified as $92 \%$ Hispanic. Demographic data from interviews of participants by a Spanish-speaking research assistant and written surveys in both Spanish and English revealed that, for the most part, all participating parents had attended at least some schooling in Mexico, with an average of 7.8 years for females and 6 years for males. For the adult participants, the average time living in the United States was 7.8 years (ranging from .25-21 years); that is, rather than attracting newcomers to the United States, this program seemed to draw more established residents. This may have been because these participants had been in the U.S. long enough to know how to enter and enroll in a class of this type; in other words, they knew how to navigate the system. In all of the homes at least one parent was employed, and several parents were employed at two or more jobs. The investigation set out to determine, through home visits, what the participant families demonstrated as they engaged in homework and literacy activities in the home.

\section{Phases 2 and 3: North Carolina.}

Phases 2 and 3 of the study were set in a small coastal city in North Carolina. Renowned for its beaches, the area is also known for its history, including pre-Revolutionary, Revolutionary and Civil War events, as well as early and ongoing civil rights movements. Situated in a coastal agriculture belt, surrounded by rural counties, the immediate university area is often considered more urban and metropolitan. The county has both a traditionally diverse racial makeup (79\% White, $15 \%$ African American) and has recently become home to a large number of immigrants, primarily from Latin America (5\%), but also from eastern European and African countries (U.S. Census, 2010). Many cultural and ethnic communities have developed, some thriving more than others. Residents may live in exclusive brick homes just a few blocks away from others living in decaying buildings, crowded trailer parks, and subsidized housing.

The university plays an important role in the greater area's development, and at any one time 13,000 students are residents of the city. Of the university population, $87 \%$ are white, and $13 \%$ arelisted as combined minority (Just the Facts 2011). The school of education is the secondlargest college at the university and contributes the second-highest number of teachers to the state. Faculty members in the school of education are $85 \%$ white and $15 \%$ combined minority (Just the Facts, 2011).

Phase 2 participants: Homework in the homes of professional educators. Participants in Phase 2 of the study were parents of current K-12 school age children identified by their employment in some capacity in the university college of education teacher education program. Of the fourteen participants, four spoke English as a second language and were considered international faculty. Two participants were African American and eight others were White and born in the U.S. All Phase 2 participants maintained a high degree of formal education, holding a master's degree or higher in education.

\section{Phase 3 participants: Homework in the homes of families living in subsidized} housing. Six families participated in Phase 3 of the study. The families lived in a low-income subsidized housing project, were native English speakers, and self-identified as African American. The children attended a neighborhood Title One school, indicating at least $40 \%$ of a school's students were from low-income families. This particular housing community was notorious for its high rate of violence, and thus participants living here were deemed as at-risk as 
victims of violent behaviors, unemployment, under-schooling, and basic disenfranchisement from the larger mainstream community.

Participants were identified through membership in an afterschool program that, according to the agency website, aimed at providing support for at-risk children and families by giving residents of the community a safe afterschool environment and skills to achieve both academically and socially. All families in the afterschool program had at least one parent in the home along with children of school age. Children ranged from kindergarten through high school, with at least one family also having children younger than school age. At least one family had a working parent in the home. Participants were contacted by the director of the afterschool program and asked to participate.

\section{Data Collection \& Analysis}

This study investigates the homework practices of demographically varied families (Gutierrez, 1995) from a Funds of Knowledge approach (Moll \& Greenberg, 1990; Moll et al., 2000). The investigation originally set out to determine what the participant families described as their own best practices to accomplish homework in their homes with their children.

Seven families volunteered for Phase 1 of the study, which took place in participants' homes. Home visits were seen as a way to support a mutual sense of trust and build a stronger relationship between the home and the school program (HOMEWORKS, 2014; Ginsberg, 2007; Worthy \& Hoffman, 2001), and in this case, the researcher. Home visits can be a gateway for strengthening communication, by making sure that families know that they are cared about outside of the classroom. They can reveal a family's special interests and hobbies. Discourse patterns and literacy practices not brought out in a classroom setting can be made visible (North Central Regional Educational Laboratory, 1994).

The purpose of the home visits was described to participants as the opportunity to share what they would like teachers and the research team to know about the homework and literacy practices they used in their homes. Participants were asked by the ESL classroom teachers to volunteer to open their homes to the researchers, who they were familiar with through participation in the larger study. Participants made appointments according to their own convenience, when they had returned from work and children were home. Generally a conversational approach to the interview was taken. Upon entry to the homes, researchers were welcomed by parents and asked to sit down. Although the homes could often be described as small, there were both communal and private areas in each of them. At each visit the homework was carried out in a communal area with multiple family members present. A university-funded research grant gave money for a small gift for each family for their participation, which included school supplies and a children's book.

In Phase 2, drawn from a convenience sample of faculty colleagues, data collection differed because of the closeness and familiarity of the faculty researcher with the participants. Fourteen parent participants volunteered, representing a total number of 18 children. In all cases the faculty researcher knew the families on both a social and a professional level. For this reason, a graduate student researcher conducted the interviews in the faculty members' offices and did the initial coding of the results. This data collection method, while different from the other two phases of the study, addressed the same talking points (Fox, 2003). Data was limited, however, by not including the children's interactions and demonstrations as in the first two phases of the study. No monetary award was given. 
Phase 3 of the study drew from a group of participants identified by their enrollment in an afterschool program that served a population of children all living in a subsidized housing community. It differed in that participants were invited to participate by the program director and gave them the option of a home visit or an interview at the afterschool site. Six parents volunteered, representing a total of 13 children. Coincidentally three of the six families chose the home visit setting and three chose the afterschool setting. Home visits were conducted by the faculty researcher, who some of the parents had met as a volunteer at the afterschool program and holiday events. Home visits were described as a way for participants to share what they would like for teachers and the research team to know about the homework and literacy practices they used in their homes. A monetary award of $\$ 50$ was awarded, paid for by a university research grant.

In all three phases of the study the participants received the same lis $t$ of talking points for preview prior to the visit and/or interview, emphasizing that the focus would be on what was already occurring in the home. These points were typed and distributed to participants (e.g., what type(s) of homework does your child have? How does the teacher manage the homework; is it daily or given as a packet for the week? Where does your child do his/her homework?)

Participants in Phase 1 of the project received the questions in both Spanish and English. These talking points are shown below.

1. How many children do you have and what are their ages?

2. How often does your child (children) have homework? Can you describe it to me?

3. How does the homework get accomplished?

4. How would you describe how she/he does the homework - alone, with help from siblings, with help from parents, with monitoring? Other?

5. Where does the homework take place?

6. How long does it take to do the homework?

7. How is the homework organized or put together?

8. Is the homework graded? Is it included in a grade? What kind of feedback [award] is received?

9. What would you like to say to the teacher about the homework?

A total of 27 families were interviewed in phases one, two and three of the study. Audio recordings, still shots, and field notes were used to record data. Field notes were transcribed, with the recordings used to clarify discourse and give additional information. Still photos were analyzed for additional sources of print. Results were analyzed both as individual cases and as group findings. Trends in the data were coded according to the three groups and across groups. Participants were assigned pseudonyms. Adults were coded within the family, such as Mr. Sanchez or Mrs. Johnson, with children given first names.

\section{Results}

The results of the study showed that homework had multiple interpretations, benefits, uses, and relevance for families. Regardless of native language background, a language and cultural transference occurred from school to home through the homework. 


\section{Results of Phase 1: Homework in the Homes of Spanish Speaking Families}

Analysis of home visit data indicated that families were involved in the homework process in the home. English language homework and other sources of print from the school were used by multiple family members in the homes of all seven participating Spanish-speaking families. Homework was used as an important resource for print by parents, younger and older siblings; all found benefits from the use of the child's homework and the shared time with the English materials.

Home visits revealed that homework was carried out in a central location of the home, such as a table in the eating area, another time a sofa, and another time a chair bottom serving as a desk for both the mother and the two children. Parents sat shoulder to shoulder or across a table from their children during the homework practice. In no case was a quiet setting with an individual lamp or desk used, as was previously suggested in school and parenting communication from the family literacy classes and the literature on best practices for homework (Beaulieu \& Granzin, 2004; Rosado, 1994; Teft, 2000; Unger, 1991).

Household chores were completed prior to or set aside during homework time. As in the afterschool homework lab, parents were involved in the homework process; parents handled and wrote on the child's homework. This shared processing of the homework served to initiate the homework and model for the child proper homework completion. The close physical contact between the parent and child around the homework was sometimes used for encouragement and other times for redirection. The physical stance in the home was close, with all attention focused on the homework and school materials.

Homework began with the unpacking of the book bag, most often initiated by the parent, with other family members looking on. Parents and siblings handled and examined the school materials from the book bag. Besides homework, the class work and informational flyers were held, examined, valued, and shared as school correspondence, often described in Spanish and read aloud in English by the school age child. For example, Samuel explained the food pyramid to his mother in Spanish from a flyer in English sent home by his first-grade teacher. His two younger siblings looked on, leaning across his lap and over his shoulder, and then discussed in Spanish with each other the foods as he passed the flyer to them. They then colored the paper and traced over his lettering. Finally, they wrote approximations of their own names alongside his name written at the top of the paper.

Another example of sharing school resources was evident in the use of a school book order. Mr. Sanchez explained how each month his sixth-grade son, Marco, brought home a commercial book order form distributed by his classroom teacher. He described how each family member took a turn to order a book of their choice. The book order arrived on the day of the home visit, and the English-language book was lying in view on the table where homework was being done. The mother explained that the family took turns ordering one book each month from Marco's book order. The father had received his choice, a non-fiction book about astronomy, this month. When asked why he had chosen this particular book, he replied that he knew many names of constellations in Spanish as the night sky was "brilliant with stars" at their home in Mexico. He hoped to learn the names in English so that he could teach Marco about the constellations visible in California and Mexico in both languages.

Statements of Spanish-speaking parents in this phase of the study suggested that they recognized homework as a way for them to learn about mainstream school practices. A striking example was made evident with the Ortega family. Mrs. Ortega discussed how her first-grade son had shown her a new way to do subtraction by using a number line, as compared to how she 
had learned in Mexico using tally marks. Mrs. Ortega went on to say that she would now teach her preschool age daughter, Rosario, how to subtract using a number line, as done in her son's classroom, as well as teaching her children to use tally marks as she had learned.

Aside from learning English and mainstream school practices, homework was used as a tool for maintaining academic Spanish. In one case, English spelling words were translated for Spanish spelling practice. On this home visit Marco was seated between his two parents. They watched him as he wrote his spelling assignment, periodically discussing in Spanish the English vocabulary in the homework. Mr. and Mrs. Sanchez showed how they each kept a composition book where they recorded words that they copied from Marco's spelling homework. When he completed his assignment they began a three-way bilingual discussion of the words, translating them orally to Spanish. Mr. Sanchez then gave Marco a spelling quiz with the same words now translated into Spanish. Mr. Sanchez took on a teacher stance, holding himself away from his son, and calling the words out in a numbered fashion. At the conclusion of the ten-word quiz, Mr. and Mrs. Sanchez together checked his words, telling him how many he spelled correctly. Marco then took on the teacher stance, telling his parents to number their papers. He then called his English spelling words out to his parents in the same manner as they had previously done with him. This practice was routine, systematic, and very school like.

In all cases in Phase 1 of the study, homework was seen as a collective or multiple family-member activity where both English and Spanish were used. Parents cited this practice as an intentional homework strategy. Older children were observed routinely helping younger ones with their homework. In one apartment complex, families had started an informal homework club, where children of mixed age and gender went to each other's homes to do homework within the family group. During one home visit, a neighborhood girl in third grade was visiting the Ruíz home during homework time. Socorro, a first grader in the home, was working on a math page with her mother at the dining table. The older girl asked if she could help Socorro with the homework and then, in what language she preferred the assistance. Socorro's mother looked on, smiled, and interacted with the two as they did the remainder of the homework page. The three continued to discuss the math problems, which centered on telling time, in Spanish, as Socorro wrote the answers in English. As in the introductory example from the Ortega home with Samuel sharing his work with his younger siblings, school materials and practices were used intentionally in a collective method to benefit multiple users.

\section{Results of Phase 2: Homework in the Homes of Professional Educators}

Parents in Phase 2 of the study voiced concern more over the purpose of homework and how it benefited their own child, expressing the need for homework to be more individualistic to be meaningful:

One of the things I'm big on with homework is that it needs to be targeted to that child. If that child isn't struggling, why should they have more practice? If you want to challenge them, then certainly send something else home with them. Um, but you know this whole concept of having homework just because we want to have homework is a little silly.

Ms. Wills, a parent of Brianna, a fourth grader and Mike, an eighth grader, went on to say, "I'm not a big fan of homework because they have been in school for 6-plus hours a day. Unless they are kids that do not pay attention in school, I don't think homework is necessary". 
Ms. Stuart, a parent of two high school children, likewise described the amount and quality of homework as detrimental:

I'm one of those parents that doesn't support a lot of homework; I've seen it with both of my children going through school. Hours of what I like to call kill and drill, for example, and they particularly hit in in the math areas.

Parents in this group were concerned that the homework was generic, not necessarily geared to their own children's needs. Mr. Doogan expressed concern about the meaningfulness of his first grade daughter's homework, especially in regards to how it connected the academics of the classroom to his individual child: "I've never seen the real value unless it is going to be personal and meaningful and connected to what she's doing in school." Ms. Lacoste, the mother of Lorena, a second grader, said:

At her previous school, one of the reasons I disliked the homework assignments so much is because I didn't feel they were targeted to my child at all. The teacher gave the same assignment to every child, no matter what. So for my daughter it was basic repetition. She would say, "It's boring, I don't want to do this, it's awful." So there were times when I would say, "Okay, you don't have to do it." She's spent the whole day at school, she's gone to afterschool, and um yeah, I'm just like that's stupid. Which is one reason we made the conscious choice to move to a school where homework isn't required.

Parents in this group expressed a desire for less-to-no homework. The negative impact of homework on family time was mentioned again and again. Mr. Wade said, "I sometimes wonder if the homework is more for the parent than for the child. In other words, is it a way for the school to organize our family time more than to help my child with academics?"

Likewise, Mr. Nthabi expressed concern over the time spent on homework rather than free time and/or family time:

I think homework is necessary, but sometimes I think it is stressful too much. Kids need to be a kid. There are a lot of things kids can do that would be very enriching besides homework, so you know that's my opinion. It can't take up all day and night after they get home from school. Family is important.

This opinion, that homework was in opposition to family time, was expressed in this group only, but was consistently expressed by every participant in this phase of the study.

Parents in this group tended to be concerned about the quality of the homework. Ms. Marten said, "Well I do think homework can be positive, as far as reinforcing skills, but I think it's often used so ineffectively in schools today." Mr. Brock, a parent of three elementary age children, stated: "Most of the work is pulled from some kind of trade publication, [teachers] just simply copy things and sometimes they are poorly put together." The lack of meaningful feedback was described by several parents. Ms. Robertson described the importance of feedback as a teaching tool: "My other big thing is the feedback is that teachers assign it and then don't give real feedback. Especially in middle school, they check off that you did and then the kids don't truly do it and if they did a problem wrong they don't realize it. A lot of kids don't have someone at home to guide them or help them, so they need that feedback." Mr. Brock described 
his reaction to the amount of work the child put into the homework as compared to the teacher's feedback:

Most of it comes back with some mark on it, might be a stamp or a single word. There are some things that I see and I just have this visceral reaction to because you see a worksheet come home that the kids have done that is 25 or 30 problems and at the top of it says minus one. You could have written plus 24 instead of sending a message to kids that it's not good enough.

Several parents characterized homework as having the positive effect of teaching independence. Ms. Purdue voiced concern that her kindergarten son's school "no homework" policy might negatively affect his independent study skills when he moved to middle and high school. Ms. Clarke said of Brendan, her sixth-grade son, "The teachers are trying hard to help kids learn to be responsible and I appreciate that a lot."

In spite of the statement that homework developed independent study skills, thirteen of the fourteen participants described their child's homework setting as in the kitchen or living room areas. In fact, the word "we" was used again and again as parents describe how the homework was done, showing again the collective nature of the homework practice. Ms. Clarke said of Brendan's work, "Since most of it is project base, the greater majority is stuff we help him with."

As in the other two groups, parents again saw homework as having significance as a communicative tool about school practices - a way to be informed about the school curriculum. Ms. LaCoste said, "I think some parents feel like that's the only way they'll know what their kids are doing at school, because they will see their kids doing homework and they will see their kids either struggling or not struggling and that's their barometer for what's going on."

This parent group used mainstream school jargon in a natural way, with the majority of them using at least one label or name for a school program during the course of the interview. This was unique to this group. Mr. Driscoll said, "My fourth grader has online resources, but my eighth grader does Study Island. Have you heard of Mondo for algebra? It's like links of connections to what they are already doing in school." Ms. Reese described the homework program for Trey, her first-grade son, from memory: "The work is posted online the week before, so even for the spelling pretest, which is always on Monday, the words are there so students can study it. If they make a 100 on the pretest they are given a different set of words, but they do have the time to prepare for that. They use a program called Spelling City, with links to web resources. Another thing that makes homework easier, at least spelling, is a 3 by 3 grid like a tic-tac-toe grid. The activities change within the grid and they just have to do 3 in a row, diagonal or column." From this data, it was evident that parents had ownership of the school curriculum, were easily able to speak about it, use teacher jargon, and feel comfortable manipulating and working with resources.

\section{Result of Phase 3: Homework in the Homes of Families Living in a Subsidized Housing Project}

Phase 3 parents stated they were less likely to visit the school during the day and were less likely to be involved in parent committees at the school in the evenings. Walking or public transportation would be the only way to visit school, and parents expressed concern regarding walking in the neighborhood. Instead, they were more likely to put significance on homework as 
a way to learn about the school curriculum and the status of their child's progress. Ms. Johnson, the parent of a first-grade boy, Lewis, and a tenth-grade girl, Sarena, was representative of other parents in this group. She told how homework helped her to know what Lewis "should be learning." She described how he taught her about reading and spelling as he was taught, such as when he showed her how to make new words by deleting the initial sound and adding a new one. She said, "He came out with that and I said, 'That is beautiful!"” When the researcher described this practice as a phonemic awareness strategy, she said, "Yes, the teacher had that on his report."

Several parents voiced the need for more homework. Ms. Fields, the parent of three boys under 9 years of age, said, "I asked for more homework...He [third-grade son] finishes it too early He says he did it all at school. I like for them to sit together and have that to do together." Ms. Johnson described her situation with her first-grade son: "He gets home at 2:30, and it's a long time before bedtime, and I can't take him to the playground all day every day." Ms. Johnson, like other parents in the housing project, did not allow their children to play outdoors without the parent present in the nearby communal playground. Parents in this group spoke of positive memories of one special teacher and school personnel who had made a difference in their or their child's lives. These were very specific comments, highlighting one particular teacher's attention to details, courtesy, or time spent together. Ms. Johnson recalled a librarian that had spent time with her in ninth grade, sharing Shel Silverstein poetry with her during the lunch period. She asked the researcher if she knew of his poetry and said she had been looking for his books to share with her children but hadn't found any at yard sales or the used bookstore. Later, when discussing the honorarium for participation in the study, she asked if she might have the book, Where the Sidewalk Ends (Silverstein, 1974), rather than the financial gift for her participation.

When the researcher later returned to deliver a copy of the book, Ms. Johnson turned to the page of a favorite poem and read the title aloud to her tenth-grade daughter:

Ms. Johnson: Let me see. Page 52. Sarah Cynthia Sylvia Stout...

Sarena: Momma, is that your book? You got your book?

Ms. Johnson: Yeah it's it. And it's still here. Listen here: "Sarah...."

She proceeded to read the poem aloud, exclaiming to the researcher, "I can't believe you did that," implying her surprise in receiving the book as promised.

Homework was seen as a way to progress academically; thus when homework was not completed or out of reach for the parent, it was seen as a concern. Ms. Johnson said of her highschool age daughter, "I try to help her but she already knows more than me. She's real smart, and I told her to keep working at it and ask for help. I go off! 'I don't want you to be like me!'” She, along with other parents, expressed fear in not being able to support their children academically as they progressed: "I need serious help in order to help my children. I'm serious. I am scared about what's going to happen next year 'cause I'm not going to be able to help him [Lewis, first grade]."

This concern regarding supporting children academically was transferred to teachers. Parents valued teachers who gave feedback and grades on the homework. Homework feedback as a teaching tool was seen as an important way for the parent and child to learn. When not given, it was seen as a negative use of the child's time. Ms. Jackson added, "I see that the same 
things she got wrong on her homework are the same things she gets wrong on her test. They get rewards for just turning it in, not if it is correct."

All feedback from the teacher was valued, even if it was a sticker or smiley face with no comments. The parents saw these teachers as more organized. Conversely, when teachers did not return homework with comments or did not reward the child for homework well done, these teachers were judged as unfair and disorganized. Ms. Jackson, the mother of two children, said "I don't think she cared that she had spent the time." Parents showed pride in child's progress and displayed homework projects. Ms. Johnson called to Sarena to bring a homework sample from a personalized scrapbook to show how she had helped Lewis complete a "turkey" project. The teacher's directions were to decorate the turkey, which was a plain outline of a turkey using basic shapes on copy paper. Ms. Johnson and Lewis had used plastic hair beads belonging to Sarena to create a turkey using a type of mosaic effect. Both Ms. Johnson and Lewis seemed proud for the researcher to photograph the work to show as evidence of time spent on homework. "I thought this was so cool," Ms. Johnson said.

Parents also appreciated homework being consistently and regularly assigned. Practices such as spelling contracts that repeated from week to week, a system that delegated reading homework to Monday and Wednesday and math homework to Tuesday and Thursday, and a teacher who had a weekly packet were all noted as being organized and effective. Parents knew the routine of the homework and were able to restate it in detail from memory. Ms. Fields, the mother of three school-age children, stated:

My preschooler gets a weekly packet for Monday-Thursday. He writes his letters, name, matches colors, and gets a cutting sheet. My first grader gets a list for the week with 15 spelling words. He reads a book a week and has 10 or 5 vocabulary words. My older one is in Special Ed. He gets a pack for the week and has to read 30 minutes a day. I go over it and I give them a test. They have to write their words 5 times a day.

Likewise, Ms. Sampson described in detail the homework routine in her household, including how she added to the routine with her own school-like instruction: "After we do his homework we read every night and then he reads to his little brother." Parents living in the subsidized housing project saw homework as a link to school practices, to meaningful collective family activities, and to a better education future. More, rather than less, homework was requested. Feedback on homework was seen as informative and valued. Homework took on the role of a family event and was done in a collective atmosphere among other family members. Parents took on the role of teacher, providing additional school-like activities. Teachers and materials were valued.

\section{Summative Findings}

Interview data from Phases 1, 2, and 3 participants revealed that homework was generally carried out in a central location of the home. In every home of Spanish-speaking families and families living in subsidized housing, homework was accomplished at a family/group area. The sofa, coffee table, kitchen table and the seat of a chair with a stool pulled up were used as homework areas. This was also included in responses by education faculty members, such as the kitchen table as the homework setting for two children while the parent prepared dinner. In no case in any of the three settings studied was a quiet setting with an individual lamp or desk 
described, as was suggested in the literature on best practices for homework (Beaulieu \& Ganzin, 2004; Cooper, 2001a; HOMEWORKS, 2014; Rosado, 1994; Spalding, 2004; Teft, 2000; Unger, 1991; Vatterott, 2012).

Our data indicate that parents were highly involved in the homework process and that multiple family members found benefits from the use of the school age child's homework. Homework provided information for families and was used in both intended and creative ways. In Phase 1, with Spanish-speaking parents, rules such as "Don't begin your homework until your parents are home," helped assure that homework was used as an important artifact of print for parents and siblings. Homework was used as a tool for learning English by multiple family members. Likewise, homework was used as a model of academic practice that could then be switched to practicing the home language, in this case Spanish. Phases 1, 2, and 3 parents used homework as discussion prompts about academic methods for learning. It was used to display family pride, as in Phase 3 parent Ms. Johnson's example of the turkey project she and Lewis made together using Sarena's hair beads.

In all phases of the study, homework was seen as a family activity. Younger children (not yet of elementary school age) participated by drawing, writing, and interacting during the schoolage child's homework time. Older siblings shared materials with younger children. Parents cited this practice as an intentional homework strategy. Older children were described as routinely helping younger ones with their homework. The parents of the younger children encouraged this sharing of the homework event.

Interview data from Phase 2 parents state that they saw benefits of homework as developing independence. However these parents, as in Phases 1 and 3, consistently described their intervention and involvement in their children's homework. The difference in this group's results was that they described homework in more negative terms than the other two parent groups, as in homework interrupting other quality time.

The goal of maintaining and valuing family time was made evident in all three groups. In Spanishspeaking families, English homework was discussed in the native language as a family activity. In some cases the work was read first in English and then discussed in Spanish. In the families living in subsidized housing, parents described homework as something they did together as a parentchild activity and/or something for siblings to do together. In the homes of professional educators, five of the fourteen parents bemoaned the time it took away from other activities.

\section{Limitations}

A significant limitation of the study is the inconsistency of settings for the interviews and observations. In Phase 1, participants were familiar to the researcher through a university partnership with the established family literacy program. Phase 3 participants were less familiar with the researcher but had a level of trust through the afterschool program director. The relationship of the Phase 2 participants and the researcher made it difficult to collect data in a consistent and confidential manner. For this reason, a graduate student researcher conducted interviews in an office setting, which did not allow for the home setting to be included. This limitation put a greater emphasis on the attitude about homework completion than in the other two phases, where the setting was more emphasized.

A second noted limitation was that the study originally focused on language issues. It was not until results were analyzed that the perception of the benefits of homework were found to be the key factor among the different families. This natural outcome of a qualitative study, that 
questions emerge as the study evolves, shaped the discussions as data was collected and analyzed in Phases 2 and 3.

\section{Conclusion and Implications}

Best practices for homework achievement were different for families in this study than what is often recommended in literature on homework achievement (Beaulieu \& Granzin, 2004; Canter, et al., 1988; Spalding, 2004; Unger, 1991). Homework was revealed to have a family focus with multiple goals and communicative benefits rather than solely as an individual event to build independence, as often suggested. The multiple opportunities for culturally relevant pedagogy between parents, children, and siblings were made evident in the collective processes displayed and discussed among all family groups in the study. Employing Gay's definition to shape the idea of culturally relevant homework practices, "using the cultural characteristics, experiences and perspectives of ethnically diverse students as conduits for teaching them more effectively" (2002, p. 106), we can see that homework design and organization needs to adjust and adapt to the culturally determined factors in students' lives.

Homework is a resource valued in multiple ways as an academic, social, and cultural link to the school for families. In contrast to a more drill-and-practice perspective of homework, homework is seen as a communicative tool for mainstream academic discourse. Following are three implications for teachers to tap into the multiple benefits offered through homework in the diverse families of their students.

\section{Look for ways to design homework that includes parents in the acquisition of school- like practices.}

Families who might otherwise have been isolated from mainstream schooling practices found in homework a way to negotiate the school culture within the safety of the home. The opportunity to be together as a member of a family group made the learning experience a collective one. One way to make sure homework is more easily accomplished is by taking the time at the end of the day to complete one or two homework problems, modeling the practice and using words such as, "When you do this at home, make sure you use your crayons to mark the words that end in $/$ y/ just like we do with our highlighters. Ask someone at your house to help you find more words in your house that have these same letters. Take turns writing these new words on your paper. Use crayons to draw and color these objects."

\section{Design homework to be shared by multiple generations in the home and classroom.}

Homework time was in all cases a collective family time. The printed homework page, as well as books and activities, provided families with a family activity that crossed lines of language, gender, age, and literacy level. Homework provided mainstream schooling methodology to ease the transition for younger siblings. Rather than seeing homework as a source of tears, homework offered quality time for family members. Additionally, homework is shared in the classroom to inform teachers and classroom peers about the diverse family practices, including the language of the home. Homework that includes family participation can likewise include information to be discussed when returned to the classroom. One example is when a teddy bear or stuffed animal is sent home with a journal. The family writes a journal 
entry about what the teddy bear does while spending the evening with the family. On the following day, when the teddy bear is returned to the class, the journal entry is shared in class, so that other children, along with the teacher, learn about the child's home. The teddy bear and journal are now sent home with another child, and another journal entry is written and shared.

\section{Consider homework as a tool for family members to use academic language in the translation, mediation, and practice of the home language, such as Spanish or local dialects.}

In Phase 1 of this study, minority language parents were the "mediators" and "negotiators," ensuring that the concept being taught in the homework was truly understood, via the child's native language. Just as families in the study modeled for us, teachers can have directions and/or materials printed in more than one language. Additionally, teachers can be inclusive of non-English words in homework responses. In the above sample of the teddy bear journal activity, families can be encouraged to write the journal entries in the home language, the school language, or a combination of the two. When shared in class, the child can then be a language model for others.

As a former classroom teacher, I look back at the processes I often used in designing homework and realize that I often did not understand the families' expectation for the practice. Rather than a reflection of my classroom instruction, I saw homework as a cultural expectation to satisfy school norms. I truthfully can say I wish I would have known then what I now know: that for some the family time spent on homework had a benefit of communicating school practices, for others homework provided practice in English for multiple family members, and for others homework gave children a safe and productive format for not only reinforcing but also initiating innovation of academic practices. Still, for others homework was seen as an intrusion on family quality time. By tapping into different families' own practices I could be sensitive to family needs and dynamics, respecting the true best practices occurring in the home. In this sense, homework could then be appreciated as a bi-directional communicative tool between the school and home. 


\section{References}

Amstutz, D. (2000). Family literacy: Implications for public school practice. Education and Urban Society, 32(2), 207-220.

Anderson, T. (2014). Road tested: Three ways to engage parents in high-poverty setting. Education Update, 56(9).

Beaulieu, J. \& Granzin, A. (2004). Taking the hassle out of homework: How to make homework a more positive experience for your child. Our Children Magazine, 25(2), 9-13.

Bennett, S. \& Kalish, N. (2007). The $c$ ase $a$ gainst homework: How homework is hurting $c$ hildren and what parents can $d \mathrm{o}$ about $i$. New York: Crown.

Boethel, M. (2003). Diversity: School, family and community connections. Annual Synthesis 2003. Austin, TX: Southwest Educational Development Laboratory, National Center for Family and Community Connections with Schools.

California Department of Education (2004). Current and historical levels of implementation in the community-based English tutoring program: FY 1998 to 2002 Survey Results.

California Tomorrow (1998). Update on Proposition 227. California Association for Bilingual Education Newsletter, 21(6), 3.

Canter, L., Hausner, L. \& MacMahon, B. (1988). Homework Without Tears: A Parent's Guide for Motivating Children to do Homework and to Succeed in School. New York: HarperCollins.

Chrispeels, J. \& Gonzalez, M. (2006). The challenge of systemic change in complex educational systems: A district model to scale up reform. In A. Harris \& J. Chrispeels (Eds.), Improving Schools and Educational Systems: International Perspectives. Oxford, UK: Routledge.

Colombo, M. (2005). Empathy and cultural competence: Reflections from teachers of culturally diverse children. Young Children on the Web. 1-8.

Cooper, H., (2001a). The battle over homework: Common ground for administrators, teachers and effective policies. Thousand Oaks, California: Corwin.

Cooper, H. (2001b). Homework for all—in moderation. Educational Leadership, 58(7), 34-39.

Dell-Antonia, K. (2014). Homework's emotional toll on students and Families. Motherlode: Living the Family Dynamic. Retrieved from http://parenting.blogs.nytimes.com/2014/03/12/homeworks-emotional-toll-on-studentsand-families/ 
Family Literacy Practices

Edwards, P. (2009). Tapping the potential of parents: A strategic guide to boosting student achievement through family involvement. New York: Scholastic.

Epstein, J. (2010). Partnerships then and now. New directions. Research-based programs of family and community involvement for student success. Transforming ESEA: Helping Public Schools Improve: A Public Discussion. Washington, D.C. June 29, 2010. Retrieved from http://www.edaccountability.org/Joyce\%20Epstein\%20Powerpoint\%20Presentation\%20F EA\%20June\%2029,\%202010\%20Symposium.

Fox, K. (2003). Dissertation. Instruction of Mainstream Academic Discourse in a Family Literacy Project: The Effects of California's Proposition 227 Legislation on a Parent School Population. University of California, Santa Barbara.

Fox, K. R. (2010). Homework as a collective practice for language and culture minority families. Journal of Praxis in Multicultural Education, 4(1).

Gay, G. (2002). Preparing for culturally responsive teaching. Journal of Teacher Education, $53,(2), 106-122$.

Ginsberg, M. (2007). Lessons at the kitchen table. Education Leadership, 64(6), 56-61.

Gutierrez, K. (1995). Unpacking academic discourse. Discourse Processes, 19, 21-34.

Hicks, D. (1995). Discourse learning and teaching. Review of Research in Education. Washington, DC: AERA, 49-95.

HOMEWORKS. (2014). Retrieved from http://www.teacherhomevisit.org/

Ho, H.Z., Fox, K. \& Gonzalez, M. (2007). Making schools family-friendly. In D. Hiatt-Michaels (Ed.), Promising Practices for Teachers to Engage Families of English Language Learners. Malibu, California: Pepperdine University.

Hong, S. \& Ho, H. Z. (2005). Direct and indirect longitudinal effects of parental involvement on student achievement: Second-order latent growth modeling across ethnic groups. Journal of Educational Psychology, 97(1), 32-42.

Just the Facts. University of North Carolina Wilmington. 2011. Retrieved from http://uncw.edu/aboutuncw/aboutJustthefacts.html .

Kidshealth (2015). Top 10 Homework Tips. Retrieved from http://kidshealth.org/parent/positive/learning/homework.html

Kohn, A. (2007). Rethinking homework. Principal, 86(3), 35-38. 
Moll, L. C., Amanti, C., Neff, D., \& Gonzalez, N. (2001). Funds of knowledge for teaching: Using a qualitative approach to connect homes and classrooms. Theory into Practice, 31(2), 132-141.

Moll, L. C. \& Greenberg, J. (1990). Creating zones of possibilities: Combining social contexts for instruction. In L. C. Moll (Ed.), Vygotsky and Education Instructional Implications and Applications of Sociohistorical Psychology (319-358). Cambridge, MA: Cambridge University Press

Rosado, L. (1994). Promoting partnerships with minority parents: A revolution in today's school restructuring efforts. The Journal of Educational Issues of Language Minority Students, 14.

Silverstein, S. (1974). Where the Sidewalk Ends. New York, NY: HarperCollins.

Spalding, C. (2004). Homework Tips. Retrieved from http://www.homeworktips.about.com

Teft, L. (2000). Excluded voices: Class, culture and family literacy in Scotland. Journal of Adolescent and Adult literacy, 44(2).

Unger, H. (1991). "What did you learn in school today?” A Parent's Guide for Evaluating Your Child's School. New York: Facts on File.

Unz, R. \& Tuchman, G. (1997). California Proposition 227: English language education for children in public schools. File. No. SA 97 RF 0009. Retrieved from http://www.englishforthechildren.org/fulltext.html

U.S. Census Data for North Carolina (2010). Retrieved from http://www.census.gov/census 2010/states/nc.html.

Vatterott, C. (2012). Hints to help reduce homework stress. National Parent Teacher Association. Retrieved from http://www.pta.org/2563.html 